\title{
Myocardial perfusion artifacts in left bundle branch block: A diagnostic challenge
}

\author{
Kartik Gupta, MD, ${ }^{\mathrm{a}}$ Navkaranbir S. Bajaj, MD, MPH, ${ }^{\mathrm{a}, \mathrm{b}, \mathrm{c}}$ Fadi G. Hage, $M D,{ }^{\mathrm{a}, \mathrm{b}}$ \\ and Pradeep Bhambhvani, $M^{c}$ \\ a Division of Cardiovascular Disease, University of Alabama at Birmingham, Birmingham, AL \\ b Section of Cardiology, Birmingham Veterans Affair Medical Center, Birmingham, AL \\ c Division of Molecular Imaging and Therapeutics, Department of Radiology, University of \\ Alabama at Birmingham, Birmingham, AL
}

Received Apr 1, 2019; accepted Apr 2, 2019

doi: $10.1007 / \mathrm{s} 12350-019-01717-9$

\section{See related article, pp. 536-542}

Left bundle branch block (LBBB) is usually an acquired conduction defect with the prevalence increasing with age. ${ }^{1-3}$ It occurs as a sequela of coronary artery disease (CAD), congenital heart disease, valvular heart disease, cardiomyopathy, myocarditis, and can also be iatrogenic or degenerative in nature. ${ }^{4,5}$ In patients with LBBB, the impulse from the atrioventricular node is transmitted via the slower ventricular myocardium rather than the specialized conduction system. As a result, the interventricular septum (IVS) and right ventricle free wall contract earlier than the left ventricle (LV) free wall, leading to mechanical dyssynchrony. ${ }^{6}$ This leads to an increased stretch of LV free wall, which eventually hypertrophies in response to the increased workload. ${ }^{7}$

An increasing number of patients referred for evaluation of $\mathrm{CAD}$ have $\mathrm{LBBB}$ on the resting electrocardiogram. ${ }^{8}$ Detection of significant $\mathrm{CAD}$ in these patients can be challenging due to the high frequency of artifacts observed during myocardial perfusion imaging (MPI) using single photon emission computed tomography (SPECT). These artifacts are more common with exercise stress and typically involve the IVS and cardiac apex (both supplied by the left anterior descending

Reprint requests: Pradeep Bhambhvani, MD, Division of Molecular Imaging and Therapeutics, Department of Radiology, University of Alabama at Birmingham, Birmingham, AL; pbhambhvani@uabmc.edu

J Nucl Cardiol 2021;28:543-5.

$1071-3581 / \$ 34.00$

Copyright (C) 2019 American Society of Nuclear Cardiology. artery) and may not truly reflect ischemia. This was first highlighted by McGowan et al. using Potassium-43 and Rubidium-81 in 1976, where they observed a majority $(70 \%)$ of patients had septal perfusion defect without any significant CAD on angiography. ${ }^{9}$

Among patients with $\mathrm{LBBB}$, the observed perfusion defects in the IVS may be due to significant CAD, microvascular disease, infiltrative cardiomyopathy, or artifacts (Figure 1). The non-CAD causes lower the positive predictive value of MPI in patients with LBBB leading to unnecessary invasive angiography. ${ }^{9}$

Thus current guidelines recommend the use of vasodilator pharmacologic stress with SPECT or PET MPI with regadenoson, dipyridamole, or adenosine over exercise in patients with LBBB to detect obstructive CAD. ${ }^{13,14}$ There are some nuances worth discussing regarding the use of vasodilators in those undergoing MPI. Regadenoson is thought to be more chronotropic than other vasodilators (although still much lower than exercise) and is thus expected to have more IVS imaging artifacts due to heart rate induced dysynchrony. ${ }^{4,13,15}$ But this expected observation was not seen in two small studies comparing regadenoson to other vasodilators on SPECT-MPI, and it seems that the data seen with adenosine/dipyridamole can be extended to regadenoson in patients with LBBB. ${ }^{13,16,17}$ The role of absolute myocardial blood flow (MBF) quantification using positron emission tomography (PET) MPI has been suggested to avoid misinterpretation of septal perfusion defects in patients with LBBB in two small studies. ${ }^{12,18}$

In general, PET MPI has clear advantages over SPECT including higher photon energy, improved resolution, attenuation correction, lesser radiation exposure, shorter test time, and the ability to quantify absolute MBF. ${ }^{19}$ Whether these technical advantages translate into improved diagnostic performance in 


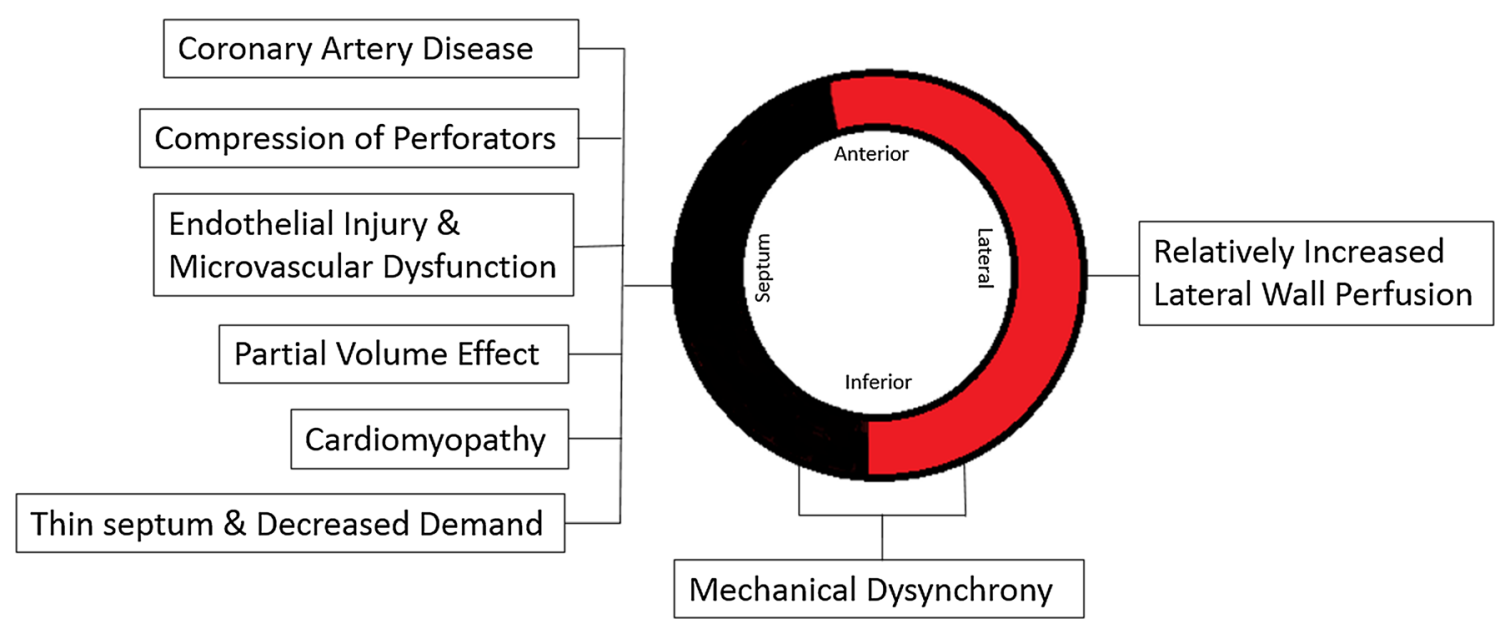

Figure 1. Etiologies of septal perfusion defect during myocardial perfusion imaging in $\mathrm{LBBB}^{4,8,10-12}$.

patients with LBBB has not been systematically evaluated. Two small studies suggest that determination of absolute MBF (using $\mathrm{Rb}-82$ and $\mathrm{O} 15-\left[\mathrm{H}_{2} \mathrm{O}\right]$ ) may improve the diagnostic performance of PET MPI in those with LBBB. ${ }^{12,18}$ In this issue of the journal, Meredith et al., ${ }^{20}$ using regadenoson, report that relative Rb-82 PET MPI without the use of absolute MBF measures can be reliably used to identify obstructive CAD in patients with LBBB. Given the small size and conflicting results with a previous O- 15 study ${ }^{12}$ we raise the following important questions that merit further research in a larger cohort:

1. How is the diagnostic accuracy of MPI (PET and SPECT) in those with LBBB affected by the choice of pharmacological stress agent?

2. Does relative PET MPI have fewer artifacts in those with LBBB and improved diagnostic accuracy for CAD as compared to SPECT-MPI?

3. Does the quantification of absolute MBF in IVS and cardiac apex improve diagnostic accuracy?

4. If yes, what is the ideal PET radiotracer for quantifying MBF in patients with LBBB?

Till future studies definitively address these questions, certain related MPI findings might point towards a possibility of CAD over the artifact. These include the presence of a reversible perfusion defect, ${ }^{21}$ an additional perfusion defect in the cardiac apex, ${ }^{22}$ involvement of other vascular territories (i.e., inferior, lateral, or anterior walls). and concomitant systolic dysfunction. ${ }^{8}$

While future studies try to address these questions, use of other non-invasive techniques like cardiac stress magnetic resonance and $\mathrm{CT}$ angiography in selected cases may alleviate patient and clinician concern and avoid invasive angiography. ${ }^{23}$

In conclusion, this study and others point out that there is clearly more to learn about myocardial perfusion imaging in LBBB patients and should encourage future research to help find the ideal technique, stressor, and radiotracer to reliably diagnose $\mathrm{CAD}$ in patients with LBBB.

\section{Disclosures}

Kartik Gupta and Pradeep Bhambhvani have no disclosures. Fadi G. Hage has received grants from Astellas Pharma, Novartis Pharma, and GE Healthcare. Navkaranbir S. Bajaj is supported by the American College of Cardiology Presidential Career Development Award and National Center for Advancing Translational Research of the National Institutes of Health under award number UL1TR001417.

\section{References}

1. Hardarson T, Arnason A, Eliasson GJ, Palsson K, Eyjolfsson K, Sigfusson N. Left bundle branch block: prevalence, incidence, follow-up and outcome. Eur Heart J. 1987;8(10):1075-9.

2. Baggish AL, Hutter AM Jr, Wang F, et al. Cardiovascular screening in college athletes with and without electrocardiography: A cross-sectional study. Ann Intern Med. 2010;152(5):26975.

3. Eriksson P, Hansson PO, Eriksson H, Dellborg M. Bundle-branch block in a general male population: the study of men born 1913 . Circulation. 1998;98(22):2494-500.

4. Surkova E, Badano LP, Bellu R, et al. Left bundle branch block: from cardiac mechanics to clinical and diagnostic challenges. Europace. 2017;19(8):1251-71.

5. Imanishi R, Seto S, Ichimaru S, Nakashima E, Yano K, Akahoshi M. Prognostic significance of incident complete left bundle branch 
block observed over a 40-year period. Am J Cardiol. 2006;98(5):644-8.

6. Auricchio A, Fantoni C, Regoli F, et al. Characterization of left ventricular activation in patients with heart failure and left bundlebranch block. Circulation. 2004;109(9):1133-9.

7. Voigt J-U. Cardiac resynchronization therapy responders can be better identified by specific signatures in myocardial function. Eur Heart J - Cardiovasc Imaging. 2015;17(2):132-3.

8. Higgins JP, Williams G, Nagel JS, Higgins JA. Left bundle-branch block artifact on single photon emission computed tomography with technetium Tc $99 \mathrm{~m}$ (Tc-99 m) agents: mechanisms and a method to decrease false-positive interpretations. Am Heart J. 2006;152(4):619-26.

9. McGowan RL, Welch TG, Zaret BL, Bryson AL, Martin ND, Flamm MD. Noninvasive myocardial imaging with potassium-43 and rubidium- 81 in patients with left bundle branch block. Am J Cardiol. 1976;38(4):422-8.

10. Ono S, Nohara R, Kambara H, Okuda K, Kawai C. Regional myocardial perfusion and glucose metabolism in experimental left bundle branch block. Circulation. 1992;85(3):1125-31.

11. Vaduganathan P, He ZX, Raghavan C, Mahmarian JJ, Verani MS. Detection of left anterior descending coronary artery stenosis in patients with left bundle branch block: exercise, adenosine or dobutamine imaging? J Am Coll Cardiol. 1996;28(3):543-50.

12. Koepfli P, Wyss CA, Gaemperli O, et al. Left bundle branch block causes relative but not absolute septal under perfusion during exercise. Eur Heart J. 2009;30(24):2993-9.

13. Henzlova MJ, Duvall WL, Einstein AJ, Travin MI, Verberne HJ. ASNC imaging guidelines for SPECT nuclear cardiology procedures: Stress, protocols, and tracers. J Nucl Cardiol. 2016;23(3):606-39.

14. Verberne HJ, Acampa W, Anagnostopoulos C, et al. EANM procedural guidelines for radionuclide myocardial perfusion imaging with SPECT and SPECT/CT: 2015 revision. Eur J Nucl Med Mol Imaging. 2015;42(12):1929-40.

15. Andrikopoulou E, Hage FG. Heart rate response to regadenoson: Making the case for its value in clinical practice. J Nucl Cardiol. 2016;23(3):575-80.
16. Palani G, Karthikeyan AS, Gordon J, Ananthasubramaniam K. Can regadenoson pharmacologic SPECT be performed effectively in patients with left bundle branch block or paced rhythm patients? A retrospective comparison to adenosine SPECT. World J Cardiovasc Dis. 2013;03(02):6.

17. Thomas GS, Kinser CR, Kristy R, Xu J, Mahmarian JJ. Is regadenoson an appropriate stressor for MPI in patients with left bundle branch block or pacemakers? J Nucl Cardiol. 2013;20(6):1076-85.

18. Falcao A, Chalela W, Giorgi MC, et al. Myocardial blood flow assessment with 82rubidium-PET imaging in patients with left bundle branch block. Clinics (Sao Paulo). 2015;70(11):726-32.

19. Murthy VL, Bateman TM, Beanlands RS, et al. Clinical quantification of myocardial blood flow using PET: Joint position paper of the SNMMI cardiovascular council and the ASNC. J Nucl Med. 2018;59(2):273-93.

20. Meredith D, Cremer PC, Harb SC, Xu B, Mentias A, Jaber WA. Initial experience with regadenoson stress positron emission tomography in patients with left bundle branch block: Low prevalence of septal defects and high accuracy for obstructive coronary artery disease. J Nucl Cardiol. 2019. https://doi.org/10. 1007/s12350-019-01681-4.

21. Feola M, Biggi A, Ribichini F, Camuzzini G, Uslenghi E. The diagnosis of coronary artery disease in hypertensive patients with chest pain and complete left bundle branch block: utility of adenosine Tc-99 m tetrofosmin SPECT. Clin Nucl Med. 2002;27(7):510-5.

22. Alexanderson E, Mannting F, Gomez-Martin D, Fermon S, Meave A. Technetium-99 m-Sestamibi SPECT myocardial perfusion imaging in patients with complete left bundle branch block. Arch Med Res. 2004;35(2):150-6.

23. Mordi I, Stanton T, Carrick D, et al. Comprehensive dobutamine stress CMR versus echocardiography in LBBB and suspected coronary artery disease. JACC Cardiovasc Imaging. 2014;7(5):490-8.

Publisher's Note Springer Nature remains neutral with regard to jurisdictional claims in published maps and institutional affiliations.' 